\title{
Periodicity of spawning aggregations of coral trout Plectropomus leopardus (Pisces: Serranidae) on the northern Great Barrier Reef
}

\author{
Melita A. Samoilys* \\ Northern Fisheries Centre, Department of Primary Industries, PO Box 5396, Cairns, Queensland 4870, Australia
}

\begin{abstract}
I investigated seasonal, lunar and diel patterns in the spawning behaviour of a serranid, the common coral trout Plectropomus leopardus, on the Great Barrier Reef, Australia, using underwater visual census surveys. The study was conducted at Scott and Elford Reefs, 2 mid-shelf reefs off Cairns, for 4 and 3 yr, respectively. At each reef, coral trout aggregated and spawned at the same 'primary' aggregation site in each year. Primary sites are defined as those with the largest aggregations of coral trout. Spawning activity, though not limited to, was concentrated at primary sites. The aggregation site at Scott Reef measured $1700 \mathrm{~m}^{2}$ in area, and that at Elford Reef $3200 \mathrm{~m}^{2}$ Maximum numbers of coral trout recorded in these sites were 128 fish at Scott Reef and 59 at Elford Reef. Coral trout aggregated and spawned at the primary sites around 3 consecutive new moons each year within the period August-December, 1991 to 1993. In 1990 only 2 aggregations were detected at Scott Reef, both around the new moon. The largest aggregations were recorded at the primary site at Scott Reef: numbers of fish at the aggregation site rose from an average pre-spawning density of 3.9 fish $1000 \mathrm{~m}^{-2}$ to aggregation densities rangıng from 37.1 to 75.3 fish $1000 \mathrm{~m}^{-2}$. The median size class of aggregating fish was 41 to $45 \mathrm{~cm} F \mathrm{~F}$ (forklength) at both reefs in all years, with a maximum range of 16 to $80 \mathrm{~cm}$ FL at Scott Reef, and 16 to $65 \mathrm{~cm} \mathrm{FL} \mathrm{at} \mathrm{Eilford} \mathrm{Reef.} \mathrm{The} \mathrm{onset} \mathrm{of} \mathrm{the} \mathrm{spawning} \mathrm{season} \mathrm{corresponded} \mathrm{with} \mathrm{a} \mathrm{rise} \mathrm{in} \mathrm{water}$ temperature $\left(>24.00^{\circ} \mathrm{C}\right)$ after the austral winter. Spawning aggregations occurred for an average of $5 \mathrm{~d}$, however aggregations were not found at the sites throughout the day. The aggregations appeared to disperse in the morning and re-establish after 13:00 h. Coral trout spawned in pairs predominantly on flooding tides and when current flow at the spawning sites was minimal. Ninety-four spawning rushes were observed which only occurred during a 33 ( $\pm 4 \mathrm{SE})$ min period spanning sunset. The spatial and temporal predictability of $P$. leopardus spawning aggregations makes them vulnerable to overfishing, but also amenable to specialised management through seasonal and/or spatial closures.
\end{abstract}

KEY WOROS: Spawning aggregations Serranids Great Barrier Reef

\section{INTRODUCTION}

A large number of epinepheline serranids aggregate to spawn, frequently at fixed sites, and their reproductive cycles are often correlated with lunar or semilunar rhythms (Johannes 1978, 1980, 1981, Thresher 1984, Colin et al. 1987, Shapiro 1987, Sadovy 1996). The common coral trout Plectropomus leopardus (Lacepede, 1802) is the most abundant of the 4 plec-

- Present address: Fisheries, Department of Primary Industries, PO Box 1085, Townsville, Queensland 4810, Australia. E-mail: samoilm@dpi.qld.gov.au tropomid Serranidae found on the Great Barrier Reef (GBR), Australia. Preliminary observations have shown that $P$. leopardus form distinct aggregations to spawn, at specific locations, and at specific seasonal, lunar and diel times (Samoilys \& Squire 1994). The purpose of this study was to verify this pattern of spawning, and to measure any variation in the occurrence, size and duration of aggregations on seasonal, lunar and diel time scales. The study was conducted at 2 mid-shelf reefs to provide some measure of inter-reef variation in the formation of spawning aggregations.

The importance of coral trout to the GBR fin fishery, and the resulting focus of research on the common 
coral trout is evident in recent papers (Doherty et al. 1994, Ferreira \& Russ 1994, Rimmer et al. 1994, Samoilys \& Squire 1994, Ferreira 1995). Understanding the reproductive behaviour of coral trout is important for 2 reasons. Firstly, coral trout are hermaphrodites (Goeden 1978, Ferreira 1995), and athough evidence is still largely circumstantial, it seems likely that sex change in Plectropomus leopardus is at least partly induced by social behaviour (Sämoilys \& Squire 1994, Ferreira 1995). Social regulation of sex change has long been recognised in some sequentially hermaphroditic fishes (Fishelson 1970, Robertson 1972, Shapiro 1979) and may occur during spawning aggregations (Shapiro 1987. Shapiro et al. 1993). Secondly, spawning aggregations are frequently targeted by fishers (e.g. Sadovy \& Domeier 1994), and elsewhere this has led to the disappearance of spawning aggregations and the subsequent collapse of fisheries of groupers (Bohnsack 1989, Sadovy 1994, in press). Anecdotal information indicates that the commercial fishery on the GBR, aided by the availability of global positioning system (GPS) equipment, is increasingly targeting spawning aggregations. To assess the implications of both these factors the reproductive behaviour of coral trout needs to be better understood.

To investigate spawning aggregations I surveyed reef sites at which seasonal aggregations of coral trout had been observed by local fishers (Samoilys \& Squire 1994, L. C. Squire pers. comm.). Preliminary investigations in 1990 at Scott Reef located one major aggregation site (Samoilys \& Squire 1994), hereafter termed the 'primary site'. The present study focussed on the site identified at Scott Reef and a primary site located at neighbouring Elford Reef. This paper presents 3 years (1991 to 1993) of monitoring of spawning aggregations at both reefs and includes results of the first year's (1990) work presented in Samoilys \& Squire (1994).

\section{MATERIALS AND METHODS}

Study sites. The study was based at Scott $\left(17^{\circ} 05^{\prime} \mathrm{S}\right.$,

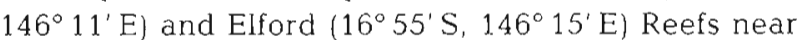
Cairns, on the northern GBR (Fig 1). On each reef the primary aggregation site was defined as the area in which the greatest number of coral trout was located during the spawning season (Samoilys \& Squire 1994). After preliminary observations, sites were mapped and reproduced on underwater paper. During censuses the position of individual fish was recorded on these maps. The site located at Scott Reef in 1990 measured $1700 \mathrm{~m}^{2}$ in area, and is described in Samoilys \& Squire (1994). The primary aggregation site at Elford Reef was located in September 1991, measured approximately $3200 \mathrm{~m}^{2}$, and was situated at the southern end of a channel which cut through the main reef from north to south. The channel was approximately $10 \mathrm{~m}$ in width at the aggregation site, but opened into a much wider lagoon to the north (leeward). The site consisted of shallow reef top at approximately 3 to $6 \mathrm{~m}$ depth on either side of the channel, with steep walls to seaward (south) dropping to a gently sloping sandy bottom at approximately 20 to $25 \mathrm{~m}$ depth. To leeward the reef sloped at approximately $45^{\circ}$ into the protected lagoon area which had a sandy bottom of approximately 16 to $20 \mathrm{~m}$ depth. Moderate to strong tidal currents were encountered running either north or south in the channel.

Censuses. Numbers and sizes $15 \mathrm{~cm}$ forklength, FL, size classes) of coral trout at the aggregation sites were counted by underwater visual census (UVC) standardised to a fixed route and duration of $25 \mathrm{~min}$, conducted by trained observers on SCUBA. Details of the methodology are given in Samoilys \& Squire (1994). A total of 218 visual censuses were conducted between 1990 and 1993 (Table 1).

On each count water temperature was measured at $15 \mathrm{~m}$ depth with a hand held mercury or red spirit ther-

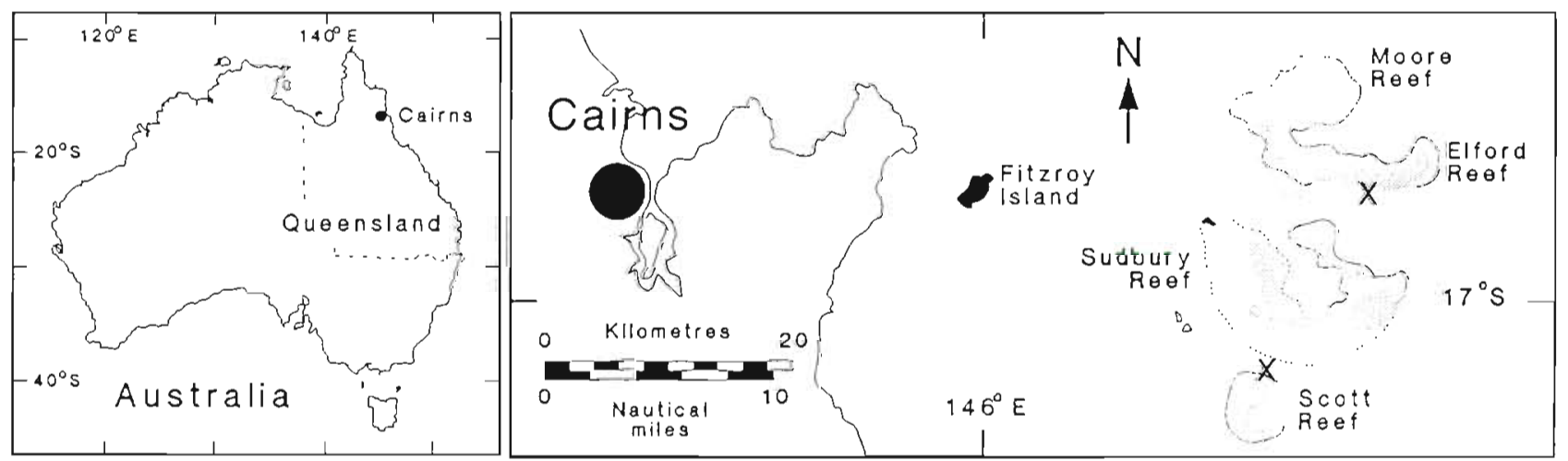

Fig. 1. Location of study sites at Scott and Elford Reefs, south of Cairns, northern Great Barrier Reef. $X=$ approximate locations of primary aggregation sites 
Table 1. Total number of visual census counts at primary aggregation sites on Scott and Elford Reefs, 1990 to 1993 . Times are A.EST (Australian Eastern Standard Time) and refer to the start of the 25 min census

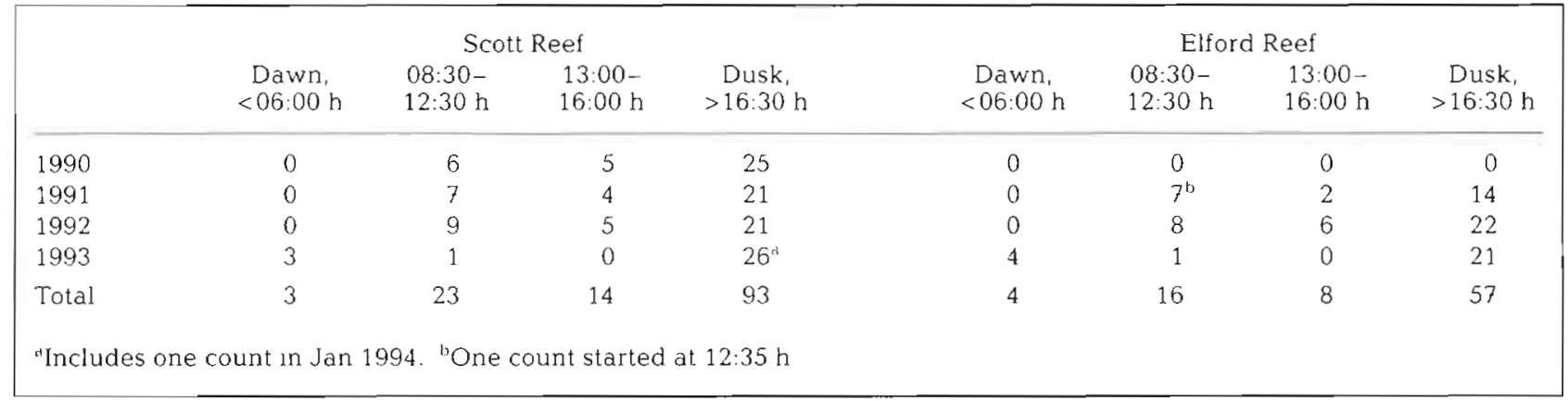

Table 2. Total number of visual census counts conducted at dusk on the primary aggregation site, summarised by lunar phase and year, at Scott and Elford Reefs. LD: Lunar day, where 1 = new moon. Actual dates of censuses are shown in Fig. 2. January 1994 is included in the 1993 year

\begin{tabular}{|c|c|c|c|c|c|c|c|c|}
\hline $\begin{array}{l}\text { Reef and } \\
\text { year }\end{array}$ & $\begin{array}{l}\text { New moon } \\
\text { LD } 28-3\end{array}$ & LD $4-5$ & $\begin{array}{l}\text { 1st quar. } \\
\text { LD } 6-10\end{array}$ & LD $11-13$ & $\begin{array}{l}\text { Full moon } \\
\text { LD } 14-18\end{array}$ & LD $19-20$ & $\begin{array}{l}\text { 3rd quar. } \\
\text { LD 21-25 }\end{array}$ & LD $26-27$ \\
\hline Scott 1990 & 4 & - & 3 & 1 & 3 & 1 & 3 & 1 \\
\hline Scott 1991 & 4 & 1 & $3^{a}$ & 3 & $5^{a}$ & - & - & - \\
\hline Scott 1992 & 8 & - & - & - & 5 & - & - & - \\
\hline Scott 1993 & 8 & 3 & 4 & - & 5 & - & 2 & - \\
\hline Elford 1991 & 3 & - & 1 & 1 & 4 & - & - & - \\
\hline Elford 1992 & 7 & 1 & 2 & - & 4 & - & - & 1 \\
\hline Elford 1993 & 6 & 1 & 3 & - & 3 & - & 1 & - \\
\hline
\end{tabular}

mometer, accurate to $0.25^{\circ} \mathrm{C}$. Visibility was estimated by stretching a fibreglass tape measure between 2 divers. All counts were conducted in visibility $>7 \mathrm{~m}$. A crude relative index of current strength was estimated in the channel of each primary site by one of 3 observers: 1 = negligible, 2 = slight, $3=$ moderate, $4=$ strong. Tidal state of each census was defined by 4 phases: ebb, flood, high tide (slack water), and low tide (slack water), using published figures for Cairns (16 $55^{\prime} \mathrm{S}, 145^{\circ} 47^{\prime} \mathrm{E}_{i}$ Queensland Department of Transport Tide Tables 1990-1993), where slack water $=$ within 60 min either side of low or high tide.

Seasonal periodicity: Regular monitoring of the aggregation sites throughout the year was conducted at dusk ( $>16: 30$ h AEST, Australian Eastern Standard Time) during a 5 or $6 \mathrm{~d}$ period around the new moon because preliminary observations found spawning behaviour and peak numbers of aggregating coral trout coincided with this period (Samoilys \& Squire 1994). Four spawning seasons (1990 to 1993) were sampled at Scott Reef, and 3 spawning seasons (1991 to 1993) were sampled at Elford Reef (Table 2). Surveys were conducted monthly during the spawning season, August to December (Samoilys \& Squire 1994).
For the non-spawning season (January to July) counts were conducted every other month, starting in 1992, at both Scott and Elford Reefs. Bad weather disrupted this schedule of sampling at dusk around the new moon 8 times in the non-spawning season and twice in the spawning season. For 7 of these an alternative moon phase or month was sampled; for the other 3 times no census was obtained.

Lunar periodicity: During the spawning season, weekly or fortnightly censuses were conducted to sample the various stages of the lunar cycle. Each of the 4 phases of the moon was assigned a $5 \mathrm{~d}$ period, and each census was done according to lunar phase (Table 2). Lunar months ranged between 29 and $30 \mathrm{~d}$ thus the new moon period varied between 5 and $6 \mathrm{~d}$. Lunar periods were based on moon light level records (data provided by the Anglo-Australian Observatory), which were divided arbitrarily into: $0.9-1.0=$ full moon; $0.0-0.1=$ new moon; $0.4-0.6=$ first and third quarters. The corresponding lunar day was calculated from lunar day $1=0.0$ moonlight. The division also gave 4 inter-phase periods (Table 2). It was intended that the 4 major lunar phases would be sampled. The majority of UVC surveys fell within these periods, but 
bad weather resulted in some sampling in inter-phase periods. Table 2 summarises the number of lunar phases sampled per month and year

Diel periodicity: To standardise counts for intra- and inter-annual and inter-reef comparisons, the majority of censuses were completed at dusk because spawning occurred at sunset (Samoilys \& Squire 1994). To determine any daily patterns in the aggregations a set of censuses were conducted during other times of the day (Table 1).

Spawning behaviour. Spawning behaviour of Plectopomus leopardus on aggregation sites involves elaborate courtship behaviour from males which culminates in spawning rushes by male and female pairs (Samoilys \& Squire 1994). The behaviour of coral trout was monitored for 30 min after each visual count to record spawning rushes. To confirm that gametes were released during spawning rushes I attempted to catch gametes from a spawning rush to identify the eggs, and rear them to larvae in the laboratory. A plankton net, of approximately $1 \mathrm{~m}^{2}$ area and $0.7 \mathrm{~mm}$ mesh size, was dragged by 2 divers through the water at the point at which a spawning pair of fish had turned at the peak of their spawning rush. Newly released eggs measure $0.81 \mathrm{~mm}$ in diameter ( $\mathrm{R}$. Garrett pers. comm.). The divers returned immediately to the boat to search the contents of the net for eggs, which were then flushed into a 21 insulated container filled with seawater The container was aerated and transported back to the laboratory in Cairns (ca $3 \mathrm{~h}$ ) Eggs were incubated in the Northern Fisheries Centre (NFC) hatchery facilities. The morphology of embryos and larvae was compared with a NFC photographic record of development of laboratory hatched $P$. leopardus eggs (Rimmer et al. 1994).

Data analyses. Spawning aggregations: For present purposes I defined a spawning aggregation as follows: an aggregation was present at the primary aggregation site if the density of coral trout at the site during the spawning season (August to December) was at least 3 times the average density of trout at the site during the non-spawning season (January to July).

Diel periodicity: Visual counts from different times of the day (Table 1) were compared using paired $t$-tests (Zar 1984), on data from days on which trout had aggregated at dusk. Data were the differences between pairs of counts from days on which 2 counts were done: morning and dusk, or afternoon and dusk, or dawn and dusk. Thus, the dusk counts were split into 3 respective groups for analyses. Data were pooled across all years. The datasets were small and normal probability plots were difficult to interpret; however, paired t-tests are robust to departures from normality (Zar 1984). Analyses involved 3 multiple $t$-tests; therefore, a Bonferroni adjusted critical significance level was used ( $p<0.017$; Siegel 1992).

\section{RESULTS}

\section{Seasonal periodicity and fish sizes}

The mean number of coral trout at the aggregation sites during the non-spawning period (January to July) was $6.58 \pm 1.09 \mathrm{SE}(\mathrm{n}=12)$ at Scott Reef and $6.67 \pm 1.38$ $\mathrm{SE}(\mathrm{n}=6)$ at Elford Reef (densities of 3.87 and 2.08 fish $1000 \mathrm{~m}^{-2}$, respectively) Thus, an aggregation was defined as $>20$ coral trout on each primary site (see 'Methods: Data analyses'). The number of coral trout on the primary sites increased dramatically during the spawning season (Fig, 2). Coral trout aggregated and spawned intermittently over an average period of $68.5 \mathrm{~d}( \pm 10 \mathrm{SE}, \mathrm{n}=4 \mathrm{yr}$ ) each year, with a range of $43 \mathrm{~d}$ (1990) to $90 \mathrm{~d}$ (1992). The timing of the formation of spawning aggregations on the 2 reefs was similar, generally occurring from September to November, with some variation in the onset and cessalion of the spawning season. For example in 1992, the season started earlier, in August, and in 1991 the season extended into December (Fig. 2). Note that counts at Elford Reef in 1991 did not start until October. Additional surveys in the 1994 spawning season, though not replicated, found spawning aggregations present in October, November and December at Elford Reef, and in October and November (December not checked) at Scott Reef (A. Roelofs unpubl. data).

At Scott Reef maximum numbers of fish in the aggregations ranged from 63 to 90 in 1990 (Samoilys \& Squire 1994), 73 to 74 in 1991, 97 to 128 in 1992 and 83 to 99 in 1993 (Fig. 2). These peaks in trout density represented magnitude changes from pre-spawning densities of up to 13-fold in 1990, 19-fold in 1991, 16-fold in 1992, and 14-fold in 1993. At Elford Reef maximum numbers of fish in the aggregations ranged from 44 to 53 in 1991, 55 to 57 in 1992, and 50 to 59 in 1993 (Fig. 2). These numbers represented magnitude changes from pre-spawning densities of up to 6 -fold in 1991 and 8-fold in 1992 and 1993.

In September 1992 and in August and September 1993, coral trout were tagged at the primary site on Elford Reef for a separate study, which may have affected the behaviour of fish, thus some of the visual counts during those months are not strictly comparable with data from other years, or with data from Scott Reef. Nevertheless, in both years the seasonal aggregation cycle at Elford Reef closely resembled that seen at Scott Reef. However, the maximum number of fish in the aggregations differed considerably between Scott and Elford reefs, with consistently greater numbers recorded at Scott Reef. The highest number recorded was 128 trout at Scott, in 1992, and the highest number at Elford was 59, in 1993 (densities of 75 and 18 fish $1000 \mathrm{~m}^{-2}$, respectively). 


\section{SCOTT REEF}

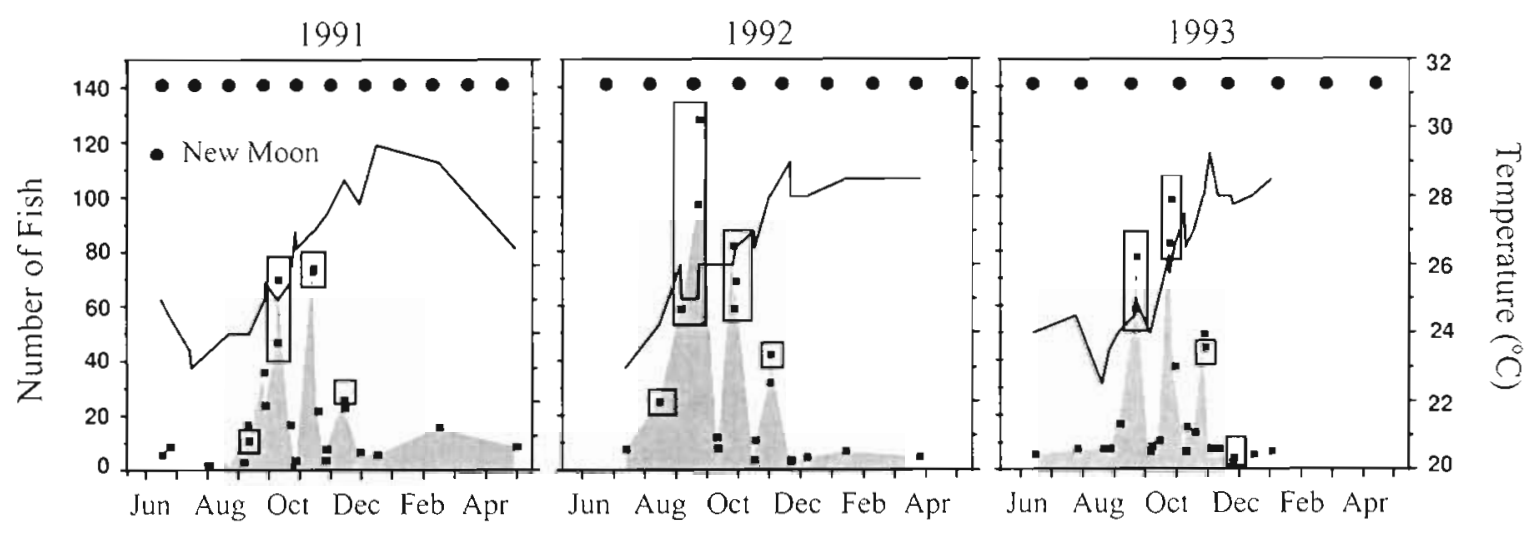

ELFORD REEF

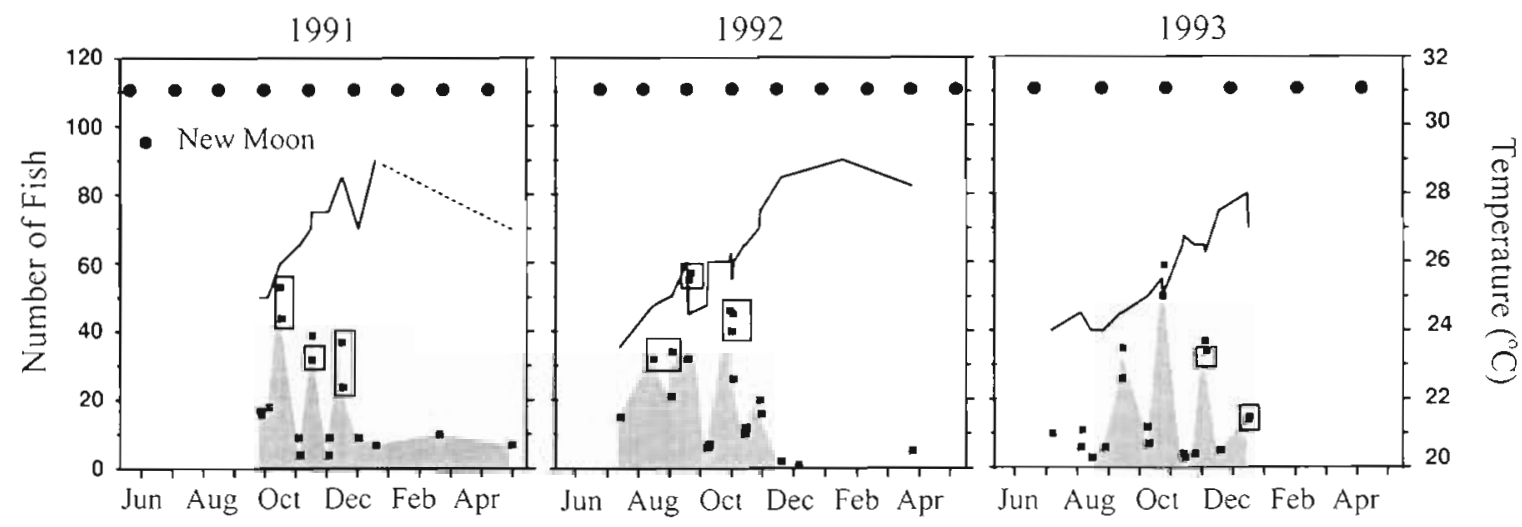

Fig. 2. Plectropomus leopardus. Number of coral trout at dusk at Scott and Elford Reef aggregation sites, 1991 to 1993. Shaded area represents total number of fish; solid line represents water temperature at $15 \mathrm{~m}$ depth. Dark squares indicate dates of census counts. Boxed areas are dates on which spawning rushes were seen. The year of each graph refers to the spawning season, August-December. Counts continued into the new year and are presented on the same graph to demonstrate the dispersal of the aggregations

Three successive aggregations formed at each primary site during each spawning season. The magnitude of different aggregations varied within a season, with predominantly 2 major aggregations and 1 smaller aggregation per year (Fig. 2). This contrasts with the first year of monitoring in 1990 at Scott Reef, in which 1 major aggregation was recorded, though a small aggregation was detected in November, and 20 trout were observed in September (Samoilys \& Squire 1994).

The majority (68 and $82 \%$, Scott and Elford Reefs, respectively) of spawning aggregations at dusk occurred on a flooding tide, and current strength was generally low at this time (Table 3).

The sizes (visual estimates) of coral trout found at the primary site when fish were aggregating ranged from 16 to $76 \mathrm{~cm} \mathrm{FL}$ at Scott Reef and from 16 to $61 \mathrm{~cm}$ at Elford Reef (Table 4). There was no evidence of a
Table 3. Current strength and tidal state during visual counts at dusk which recorded aggregation numbers of coral trout Plectropomus leopardus at Scott and Elford Reef primary sites, 1990 to 1993. Values represent percentages of the total number of counts. For tidal state $\mathrm{n}=37$ and 22 for Scott and Elford Reefs, respectively. For current strength $\mathrm{n}=30$ and 16 . respectively

\begin{tabular}{|lcc|}
\hline & Scott Reef & Elford Reef \\
\hline Current & \multicolumn{2}{c|}{} \\
Negligible & 33.3 & 62.4 \\
Slight & 40.0 & 18.8 \\
Moderate & 16.7 & 18.8 \\
Strong & 10.0 & 0.0 \\
Tide & & \\
Ebb & 13.5 & 9.1 \\
Flood & 67.6 & 81.8 \\
High tide & 10.8 & 0.0 \\
Low tide & 8.1 & 9.1 \\
\hline
\end{tabular}


Table 4. Plectropomus leopardus. Sizes of aggregating coral trout at the primary sites at Scott and Elford Reefs. Sizes are forklengths measured in $5 \mathrm{~cm}$ increments, thus $41=41-45 \mathrm{~cm}, 36=36-40 \mathrm{~cm}$, etc.

\begin{tabular}{|c|c|c|c|c|c|c|c|c|}
\hline \multirow[t]{2}{*}{ Year } & \multicolumn{4}{|c|}{ Scott Reef } & \multicolumn{4}{|c|}{ Elford Reef } \\
\hline & $\mathrm{n}$ & Median & Quartiles & Range & n & Median & Quartiles & Range \\
\hline 1990 & 680 & 41 & 36,51 & $16-76$ & - & - & - & - \\
\hline 1991 & 395 & 41 & 36,51 & $26-61$ & 229 & 41 & 36,41 & $31-61$ \\
\hline 1992 & 652 & 41 & 36,46 & $16-76$ & 388 & 41 & 36,46 & $16-61$ \\
\hline 1993 & 452 & 41 & 36,46 & $21-66$ & 241 & 41 & 36,46 & $21-51$ \\
\hline
\end{tabular}

decline in average size of fish over years at either reef; the median size class was $41-45 \mathrm{~cm}$ FL in all years at both reefs. Similarly, the quartiles indicate the size structure of the aggregating populations was consistent over years at both reefs. However, large individuals (>65 cm FL) were only observed at Scott Reef (Table 4). Numbers of sub-adult fish (16 and $21 \mathrm{~cm}$ size classes) were low (1 to 5), and showed little variation among years at either reef except for 1991 in which there was an absence of young fish at both reefs.

\section{Temperature}

In general, the first increase in trout numbers of the season corresponded with water temperatures rising above $24.00^{\circ} \mathrm{C}$ as the season of southerly winds ('winter') came to an end (Fig. 2). In 1990, 1991 and 1993 this occurred in September. In 1992 when water temperature rose earlier in August, the first aggregation of the season occurred in August (Fig. 2). The minimum temperature of the spawning season (corresponding with the peak of the first spawning aggregation) was $24.25^{\circ} \mathrm{C}$ (Table 5). The maximum temperature of the spawning season was $28.50^{\circ} \mathrm{C}$ (Table 5), which was below the summer maximum $\left(30^{\circ} \mathrm{C}\right.$. Australian Institute of Marine Science records, M. Furnas pers. comm.) for the region in 1992-1993. Maximum temperature readings for the spawning season at Elford Reef

Table 5. Water temperature (at $15 \mathrm{~m}$ depth) at the first aggregation (min.) and last aggregation (max.) of the spawning season (see Fig. 2) for Scott and Elford Reef primary aggregation sites. Monitoring at Elford Reef in 1991 started late, hence the minimum temperature was not recorded. Temperature readings between reefs were taken within 1 to $4 \mathrm{~d}$ of each other

\begin{tabular}{|ccccc|}
\hline & \multicolumn{2}{c}{ Scott Reef } & \multicolumn{2}{c|}{ Elford Reef } \\
& Min. ${ }^{\circ} \mathrm{C}$ & Max. ${ }^{\circ} \mathrm{C}$ & Min. ${ }^{\circ} \mathrm{C}$ & Max. ${ }^{\circ} \mathrm{C}$ \\
\hline 1990 & 25.00 & 27.00 & - & - \\
1991 & 25.00 & 28.50 & $?$ & 28.50 \\
1992 & 24.25 & 28.00 & 24.75 & 26.00 \\
1993 & 24.50 & 28.00 & 24.50 & 26.25 \\
\hline
\end{tabular}

were 1.75 to $2.00^{\circ} \mathrm{C}$ lower than those at Scott Reef in 1992 and 1993 (Table 5), though temperatures reached $28.00^{\circ} \mathrm{C}$ again during the 1994 spawning aggregations (A. Roelofs unpubl. data). The results suggest a temperature threshold of $24^{\circ} \mathrm{C}$ for the onset of spawning.

\section{Lunar periodicity}

The formation of coral trout aggregations was closely correlated with the new moon phase (Fig. 2), which corresponds to lunar days 28 to 3 (Table 2). Occasionally aggregations persisted to lunar day 4 , but numbers of coral trout were dropping by the first quarter moon phase (lunar days 6 to 10). If data from both reefs and 3 years are combined, new moon aggregations persisted for a mean of $4.7( \pm 0.45 \mathrm{SE}, \mathrm{n}=10) \mathrm{d}$, with a maximum of $7 \mathrm{~d}$. These values are approximate due to incomplete sampling. The lunar pattern was particularly evident in the dispersal of aggregations and their subsequent re-formation through the season. The first aggregation of the season, however, was not closely confined to the new moon phase. At this time, numbers of coral trout typically began increasing on the full moon, continued to rise through the third quarter, and reached peak densities around the new moon. This pattern was seen in 1990 at Scott Reef (Samoilys \& Squire 1994), in 1991 at Scott Reef, and at both reefs in 1992 (Fig. 2). Subsequent aggregations of the season were then closely correlated with the new moon period. The lunar pattern described here cannot be more precisely defined because it was not possible to sample every day at both reefs throughout the spawning season, and sampling was not evenly distributed.

\section{Diel periodicity}

The datasets were small and therefore comparisons between numbers of coral trout aggregating at different times of the day should be treated cautiously. Trends in the data suggest that aggregations were not well established at dawn or through the morning, but had stabilised by the afternoon (Fig. 3). Numbers of 

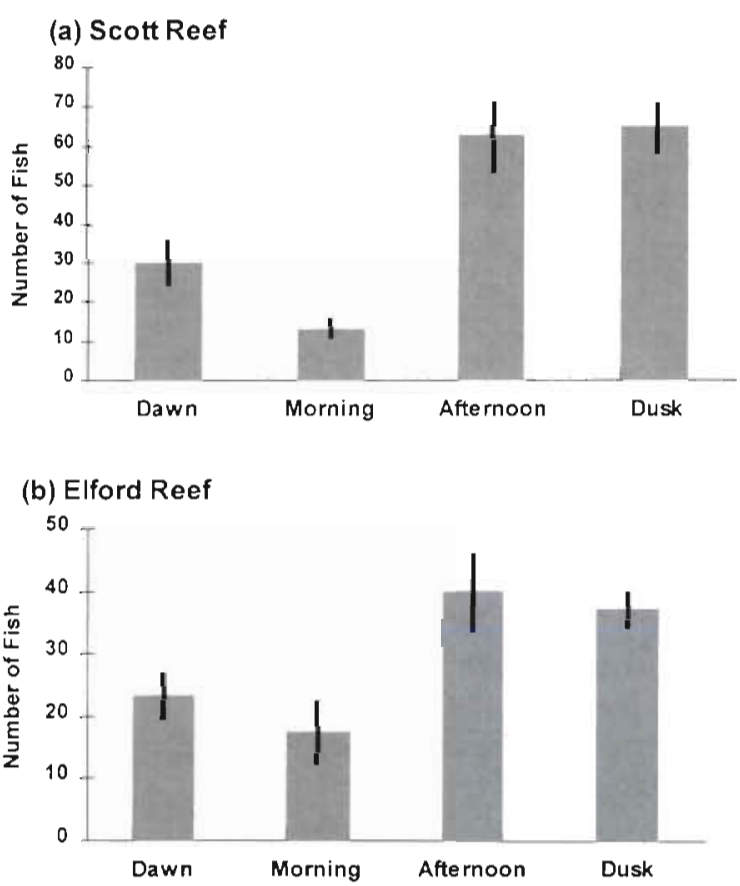

Fig. 3. Plectropomus leopardus. Mean number of coral trout on (a) Scott and (b) Elford Reef aggregation sites during aggregation periods (new moon), at different times of the day. pooled across all years. Error bars are standard errors. Dawn $=<06: 00 \mathrm{~h}$ ( $\mathrm{n}=3$ and 4 for Scott and Elford, respectively); Morning $=08: 30$ to $12: 30 \mathrm{~h}(\mathrm{n}=10,5) ;$ Afternoon $=13: 00$ to $16: 00 \mathrm{~h}(\mathrm{n}=8$ and 4$) ;$ Dusk $=>16.30 \mathrm{~h}(\mathrm{n}=21$ and 13$)$

coral trout differed significantly at Scott Reef between morning and dusk counts $(t=-4.29$, df $=9, \mathrm{p}=0.002$; Fig. 3), but differences were not significant between dawn and dusk counts $(t=-4.18, \mathrm{df}=2, \mathrm{p}=0.05)$. As indicated in Fig. 3 the aggregations had stabilised by the afternoon, and there was little difference in the total number of fish between afternoon and dusk periods $(t=-0.98$, df $=7, p=0.36)$. Fewer data were available for Elford Reef because counts conducted on 6 days in 1992 when coral trout were tagged for a separate study were not used. Nevertheless, a similar trend in the data was found (Fig. 3), though numbers of fish were not significantly lower earlier in the day compared with at dusk (morning: $t=-3.31$, df $=4, \mathrm{p}=0.03$; dawn: $t=-3.95, \mathrm{df}=3, \mathrm{p}=0.03$ ). As at Scott, the aggregation had stabilised by the afternoon and numbers of coral trout were similar to those recorded at dusk $(t=$ 0.28 , df $=3, p=0.8$, Fig. 3)

\section{Spawning behaviour}

Spawning rushes (Samoilys \& Squire 1994) between a male and female pair were observed at both primary aggregation sites in all years (Fig. 2). A total of 94 rushes were observed; these occurred during a 22 to $52 \mathrm{~min}$ period [average duration $=33( \pm 4 \mathrm{SE}) \mathrm{min}$ ] prior to darkness, from 41 min prior to sunset to 19 min after sunset. These times are not definitive since behavioural observations were only conducted for $30 \mathrm{~min}$ after a census and observations at other times were opportunistic. However, spawning rushes have never been seen at other times of the day (Samoilys \& Squire 1994, Samoilys unpubl. data). Searches with torches in the dark failed to locate coral trout out in the open. Since coral trout are diurnally active and rest hidden within the reef at night (Samoilys 1987) it seems unlikely that the coral trout spawned at night. Rushes were only seen in aggregations at the primary sites (Fig. 2), with 3 exceptions (see below). As rushes are completed in a matter of seconds in low light conditions they are difficult to see. On 3 occasions spawning rushes were observed at the primary sites when coral trout were not aggregating: at Scott Reef in September 1991 (11 fish present at the primary site); and at both Scott Reef (3 fish) and Elford Reef (15 fish) in December 1993 (Fig. 2). These observations did, however, all occur during the new moon phase. In fact all spawning rushes occurred around the new moon period (lunar days 28 to 3 ; rushes were also observed on lunar days 4 and 5 in October 1992 and 1993, Fig. 2), with 1 exception. The exception was during the full moon of September 1992: spawning rushes were observed at both primary sites and the coral trout were also aggregating (Fig. 2, see 'Lunar periodicity' above). Predation on the eggs by planktivorous fusiliers (Caesio spp.) was observed 7 times during 72 spawning rushes in 19911993. This is a minimum value since this activity was not systematically recorded during these years and it is less than half the predation rate of $27 \%$ observed in 1990 when this activity was carefully recorded (Samoilys \& Squire 1994).

At $18: 30 \mathrm{~h}$ on 18 October 1993 approximately 20 eggs were collected by net after a single spawning rush. There were no other species spawning in the same location at that time. The eggs were returned to the laboratory where they were maintained at 27.0 to $30.5^{\circ} \mathrm{C}$. By $15: 30 \mathrm{~h}$ the following afternoon 10 embryos remained alive. By 09:30 h the next day 5 of the embryos had hatched into yolk sac larvae. Most of the yolk had been absorbed, and the larvae resembled $16 \mathrm{~h}$ old coral trout larvae illustrated in NFC photographic records (M. Pearce pers. comm.). This indicates hatching occurred $23 \mathrm{~h}$ after spawning which corresponds with previous reports on the duration of development to hatching (18 to $24 \mathrm{~h}$; Rimmer et al. 1994). A further 3 embryos hatched much laterapproximately $72 \mathrm{~h}$ after spawning-giving a total of 8 larvae. On the fourth day after spawning the 8 larvae all looked the same and resembled $3 \mathrm{~d}$ old coral trout 
Larvae with well developed eyes, chromatophores present on the myomeres at the ventral posterior end, and a distinctly large but short gut; however, the oil globule was much reduced in size (M. Pearce pers. comm., Leis 1986). Unfortunately, planktivores in the live plankton feed ate the larvae on the fifth day.

\section{DISCUSSION}

\section{Spawning and aggregation behaviour}

The location of each of the primary spawning aggregation sites at Scott and Elford Reefs was stable over 4 and 3 yr, respectively. At both reefs the primary sites were well defined areas which did not vary either intra- or inter-annually. This contrasts with another serranid, Epinephelus guttatus. In Puerto Rico that species has a large and well defined aggregation site, but specific spawning sites within the area varied both intra- and inter-annually (Shapiro et al. 1993, Sadovy et al. 1994). Surveys of surrounding reef areas at Scott and Elford (that covered approximately 30 to $40 \%$ of each reef) failed to locate other primary aggregation sites, though smaller (secondary) sites were found (Samoilys \& Squire 1994, Samoilys unpubl. data). The results suggest that the spawning activity of Plectropomus leopardus is concentrated at primary aggregation sites. Samoilys \& Squire (1994) suggested that $P$. leopardus spawns at multiple sites, based on the relatively low numbers of coral trout that aggregated at the primary site on Scott Reef in 1990, but that reefs off Cairns may support only 1 or 2 primary sites, with several secondary sites. The main difference between primary and secondary sites is magnitude: the number of aggregating fish. The aggregation pattern at the primary sites was highly predictable, both spatially and temporally. I suggest this reflects physical parameters that govern a site's suitability for spawning, such as reef slope profile, current regime, and the location of the site in relation to the rest of the reef and deep water. The primary sites may represent a combination of several of such physical factors, and are therefore highly preferred or suitable spawning sites. Both the primary sites in the present study are relatively exposed reef edge sites neighbouring deep water. Such physical characteristics have been discussed in relation to spawning sites previously (e.g. Johannes 1978), but they have not been systematically quantified (but see Shapiro et al. 1988). This is difficult to do but is necessary if we are to test the hypothesis that such physical parameters are important factors for spawning fishes.

A consistent temporal pattern in the formation of spawning aggregations at the primary sites was recorded at Scott and Elford reefs, from 1991 to 1993. Plectropomus leopardus aggregated and spawned around 3 consecutive new moons within the period August-December, each year. Since the spawning season spanned 3 lunar months, aggregations consistently occurred during the new moon of October. The results do not preclude spawning at other times or locations. Though rare, spawning rushes were observed at the primary sites with no aggregation present, and during an aggregation that occurred around a full moon. Nonetheless, the lunar periodicity of the spawning aggregations observed at the primary sites was unmistakable. The results suggest that there is a strong advantage to coral trout in aggregating to spawn during the new moon period. Lunar periodicity of spawning is common in a number of reef fish species, but appears largely limited to pelagic spawners that migrate to spawn (Sadovy 1996). For example, the Nassau grouper, probably the most studied epinephelid, aggregates and spawns on 2 consecutive full moons each year in the Bahamas (Colin 1992). The possible advantages of lunar spawning cycles for larval survival (Johannes 1978, Shapiro et al. 1988), and synchronising adult behaviour (Colin et al. 1987, Robertson et al. 1990, Robertson 1991), and the proposal that aggregations may play an important role in mate selection and sex change (Shapiro et al. 1993), have been discussed for P. leopardus (Samoilys \& Squire 1994). The relevance of such hypotheses to the reproductive strategies of coral trout requires further investigation into the mechanisms of sex change and adult reproductive biology.

Lunar periodicity of spawning was not detected in histological examinations of gonads of Plectropomus leopardus (Ferreira 1995) or the congeneric P. maculatus (Ferreira 1993). Ferreira (1995) suggested that the new moon may represent a peak in spawning activity, but that coral trout spawn throughout the season. Although the present study does not unequivocally show that spawning only occurred around the new moon, the majority of spawning events were clearly linked to the new moon phase. In her analysis Ferreira (1995) used standard histological staging, and defined spawning females as those with 'oocytes in late stages of vitellogenesis from tertiary yolk globule stages to hydrating stages'. I suggest that this stage probably combines both imminent spawners and pre-spawners. Furthermore, Ferreira (1995) noted that 'running ripe' females (imminent spawners) were only found late in the afternoon during the new moon phase, although she was unable to quantify the observation. Similarly, Sadovy et al. (1994) showed that although mature (ripe) ovaries of Epinephelus guttatus were present for a 3 mo period, spawning activity was limited to only about 2 wk, based on the frequency of hydrated 
oocytes. New moon spawning in coral trout is further corroborated by the timing of larval recruitment and juvenile settlement of $P$. leopardus measured in 1990 at a neighbouring reef (Doherty et al. 1994). Larval recruitment occurred around the new moon, mean pelagic larval duration was 25 d indicating birth around the previous new moon, and back-calculated ages from juvenile coral trout confirmed both these birth and settlement times (Doherty et al. 1994). Histological assessment of coral trout gonads taken from Scott and Elford Reefs in 1992-1993 is currently in progress to further evaluate the lunar periodicity of spawning.

Spawning occurred in water temperatures between 24.25 and $28.50^{\circ} \mathrm{C}$; the annual range of the region is 22 to $30^{\circ} \mathrm{C}$ (Australian Institute of Marine Science records, M. Furnas pers, comm.). Possibly the increase in water temperature after austral winter triggers the onset of the spawning season in Plectropomus leopardus on the GBR. Evidence from the western Atlantic, Caribbean and Bahamas suggests the timing of spawning in serranids is temperature related (Sadovy 1996). Those species that occur in cooler latitudes tend to spawn during summer, whereas those in warm or low latitudes spawn at temperatures below the annual maximum (Thresher 1984, Sadovy 1996). Further evidence of the role of temperature is seen in the spawning of Epinephelus striatus, the Nassau grouper, which is confined to a narrow temperature range of 25 to $26^{\circ} \mathrm{C}$ (Colin 1992, Tucker et al. 1993).

Aggregations of coral trout persisted for around $5 \mathrm{~d}$ over the new moon. However, the fish were not at the spawning sites throughout the day. Numbers of coral trout were low in the morning, and the aggregations did not stabilise until after 13:00 h, therefore surveys to monitor spawning aggregations must be conducted in the afternoon. The low numbers of fish at the spawning sites in the morning suggests that the coral trout may hide within the reef, or disperse during that time. Since aggregations occurred for several days and feeding studies have shown that coral trout consume an average of 1 prey item daily (St John 1996), I propose that the fish dispersed to feed. This assumes that aggregations on successive afternoons consisted of the same individuals. Tagging of coral trout at Elford Reef supports this assumption (Samoilys unpubl. data). Numbers of fish were also lower at dawn compared to dusk, though not significantly. Coral trout are diurnally active and rest hidden within the reef at night (Samoilys 1987). Since the fish were aggregating until dark they were likely to remain at the aggregation site over night, and therefore would not start to disperse until daylight. No spawning behaviour was seen at dawn and dawn spawning is not known in serranids (Sadovy 1996).
Spawning rushes were only observed during a discrete ( $30 \mathrm{~min}$ ) period spanning sunset. Ferreira (1995) noted that 'running-ripe', i.e. ovulated, female Plectropomus leopardus were only captured late in the afternoon. A similar narrow time frame $(20 \mathrm{~min})$ around sunset is reported for Epinephelus striatus (Colin 1992) and for Mycteroperca tigris (Sadovy \& Domeier 1994). Dusk spawning is common in many pelagic species, especially the Serranidae (Sadovy 1996). Reduced risk of predation from diurnal eggpredators has been proposed to explain dusk spawning, but this has not been tested (Shapiro et al. 1988, Robertson 1991) Planktivorous fusiliers (Caesio spp.) were observed feeding on eggs from coral trout spawning rushes up to $27 \%$ of the time. It is possible that changing light levels might provide cues for the initiation of the final stages of egg maturation (Hoffman \& Grau 1989). The behaviour of the coral trout indicates it may be the females that govern the timing of spawning because the males court over a large portion of the day but females only respond at dusk (Samoilys \& Squire 1994, Samoilys unpubl. data). The dusk spawning pattern suggests tide is not a significant environmental cue for coral trout spawning. In contrast, diurnal spawners, such as parrotfishes, wrasses and surgeonfishes, often vary their time of spawning in response to tide (Choat \& Robertson 1975 , Thresher 1984, Hoffman \& Grau 1989, Colin \& Bell 1991). Strong ebbing tidal currents have been considered important for carrying eggs away from the reef to avoid predation (Johannes 1978), though this has not been demonstrated empirically (Shapiro et al. 1988). Although spawning aggregations of coral trout occurred during the relatively stronger spring tides (new moon), the majority of spawning events occurred on flooding tides and when currents at the primary sites were rarely strong

The rearing and identification of coral trout larvae from gametes collected from a pair-spawning rush supported the assumption that coral trout spawning rushes are spawning events (Samoilys \& Squire 1994). In some fishes spawning behaviour does not always result in the emission of gametes. Such 'pseudospawning' has been observed, though infrequently, in the demersal spawner Stegastes partitus, possibly to test male readiness, or as a means of gaining access to an egg meal (Cole \& Sadovy 1995, Cole pers. comm.). It seems unlikely that the spawning rushes of coral trout were 'pseudorushes' because they were only observed within a narrow time frame at sunset, whereas males courted over a large portion of the day. The occurrence of planktivorous caesionids feeding at the peak of some spawning rushes also confirms the presence of eggs

Both reefs in the present study are open to fishing and therefore fishing may have affected the spawning 
aggregations, particularly the numbers of coral trout aggregating. This is impossible to assess properly without data collected prior to fishing or over many years; the following conclusions are therefore tentative. Despite local concern that fishing pressure was escalating, particularly in response to the new live fish export fishery (Richards 1993), numbers of coral trout aggregating at Scott Reef did not decline over 4 yr, with similar densities measured for a fifth year in 1994 (A. Roelofs unpubl. data). In addition, there was no decline in average size of fish or numbers of large individuals over time. Nor was there any evidence of an increase in numbers of small individuals over time. However, the difference in the density and maximum size of aggregating coral trout between the 2 reefs was notable, with numbers and maximum sizes consistently lower at Elford Reef. Clearly nothing can be concluded in a comparison between 2 reefs. However, gencral observations of local fishing practices at Elford Reef, including the occurrence of commercial fishing boats at the primary site, suggested that this site was targeted more than that at Scott Reef, which could explain the lower densities and lack of large $(>65 \mathrm{~cm}$ FL) fish at Elford Reef.

\section{Management implications}

From a fisheries management perspective, it is clear that the temporal and spatial predictability of coral trout spawning aggregations makes them potentially vulnerable to overfishing, a feature that has led to the disappearance of plectropomid spawning aggregations in the Pacific Islands (Johannes et al. 1994). Fishing effort on the GBR is likely to be increasing through new commercial ventures, an increasing recreational sector, and improved navigational equipment. Possibly Plectropomus leopardus is less vulnerable to over-fishing from targeting spawning aggregations compared with other groupers (e.g. P. areolatus, Johannes et al. 1994; Mycteroperca tigris, Sadovy \& Domeier 1994; Epinephelus striatus, Sadovy in press); because aggregations are relatively small, they appear to disperse in the mornings, and spawning does occur at other sites. It has been argued that the protogynous reproductive strategy of groupers makes them more resilient to exploitation than gonochoristic populations. The suggested compensatory mechanism is a flexible social organisation which enables them to maintain high spawning success, for example by changing sex earlier (Bannerot et al. 1987). However, even if these mechanisms exist they evidently break down at high fishing mortalities because sperm becomes limited (Garratt 1986, Bannerot et al. 1987, Koenig et al. 1996, Vincent \& Sadovy in press). The existence of a considerable and apparently non-declining commercial fishery of coral trout on the GBR (Mapstone et al. 1996) supports the notion that coral trout stocks may be resilient to fishing pressure. However, our understanding of compensatory mechanisms is still poor. Sadovy (1996) suggests that the social cues required to effect compensatory sex change may be disrupted when spawning aggregations are targeted by fishers. Although the temporal and spatial predictability of coral trout spawning aggregations makes them vulnerable to fishing, it allows for specific seasonal or spatial closures and the opportunity for precautionary management strategies that simultaneously protect aggregations for further research.

Acknowledgements. This study was funded by the Australian Fisheries Research and Development Corporation, the Queensland Fisheries Management Authority, and the Cooperative Research Centre for the Ecologically Sustainable Development of the Great Barrier Reef. I am indebted to Lyle Squire, Anthony Roelofs, Jeff Bibby, Sue Helmke and Gary Carlos for field assistance and preparation of figures; to Malcolm Pearce for hatching the eggs and rearing the larvae; and to Yvonne Sadovy, Vicky Tzioumis, Beatrice Ferreira, Lyle Squire, Howard Choat and Peter Doherty for advice, encouragement and comments on the manuscript.

\section{LITERATURE CITED}

Bannerot SP, Powers JE, Fox WJ Jr (1987) Reproductive strategies and the management of snappers and groupers in the Gulf of Mexico and the Caribbean In: Polovina JJ, Raiston S (eds) Tropical snappers and groupers: biology and fisheries management. Westview Press, Boulder, p 561-604

Bohnsack JA (1989) Protection of grouper spawning aggregations. National Marine Fisheries Service, Southeast Fisheries Coastal Resources Division Rept No. CRD-88/89-06

Choat JH, Robertson DR (1975) Protogynous hermaphroditism in fishes of the family Scaridae. In: Reinboth $\mathrm{R}(\mathrm{ed})$ Intersexuality in the animal kingdom. Springer-Verlag, Berlin, p 263-283

Cole KS, Sadovy Y (1995) Evaluating the use of spawning success to estimate reproductive success in a Caribbean reef fish. J Fish Biol 47:181-191

Colin PL (1992) Reproduction of the Nassau grouper, Epinephelus striatus (Pisces:Serranidae) and its relationship to environmental conditions. Environ Biol Fishes 34: $357-377$

Colin PL, Bell LJ (1991) Aspects of the spawning of labrid and scarid fishes (Pisces:Labroidei) at Enewetak Atoll, Marshall Islands with notes on other families. Environ Biol Fishes 31:229-260

Colin PL, Shapiro DY, Weiler D (1987) Aspects of the reproduction of two groupers, Epinephelus guttatus and $E$. striatus in the West Indies. Bull Mar Sci 40:220-230

Doherty PJ, Fowler AJ, Samoilys MA, Harris DA (1994) Monitoring the replenishment of coral trout (Pisces: Serranidae) populations. Bull Mar Sci 54(1):343-355

Ferreira BP (1993) Reproduction of the inshore coral trout Plectropomus maculatus (Perciformes: Serranidae) from the Central Great Barrier Reef, Australia. J Fish Biol 42: $831-844$ 
Ferreira BP (1995) Reproduction of the common coral trout Plectropomus leopardus from the central and northern Great Barrier Reef. Bull Mar Sci 56(2):653-669

Ferreira BP, Russ GR (1994) Age validation and estimation of growth rate of the coral trout, Plectropomus leopardus, (Lacepede 1802) from Lizard Island, northern Great Barrier Reef. Fish Bull US 92:46-57

Fishelson L (1970) Protogynous sex reversal in the fish Anthias squamipinnis (Teleostei, Anthiidae) regulated by the presence or absence of male fish. Nature 227:90-91

Garratt PA (1986) Protogynous hermaphroditism in the slinger, Chrysoblephus puniceus (Gilchrist \& Thompson 1908) (Teleostei: Sparidae). J Fish Biol 28(3):297-306

Goeden GB (1978) A monograph of the coral trout. Qld Fish Res Bull 1:1-42

Hoffman SG, Grau EG (1989) Daytime changes in oocyte development with relation to the tide for the Hawaiian saddleback wrasse Thalassoma duperrey. J Fish Biol 34: $529-546$

Johannes RE (1978) Reproductive strategies of coastal marine fishes in the tropics. Environ Biol Fishes 3:65-84

Johannes RE (1980) Using knowledge of the reproductive behavior of reef and lagoon fishes to improve fishing yields. In: Bardach JE, Magnuson JJ, May RC (eds) Fish behavior and its use in the capture and culture of fishes, ICLARM Conference Proceedings, 5th edn. International Center for Living Aquatic Resources Management, Manila, p 247-270

Johannes RE (1981) Words of the lagoon: fishing and marine lore in the Palau district of Micronesia. University of California Press, Berkeley

Johannes RE, Squire L, Graham T (1994) Developing a protocol for monitoring spawning aggregations of Palauan serranids to facilitate the formulation and evaluation of strategies for their management. First progress report, August 1994. FFA Report \#94/28. South Pacific Forum Fisheries Agency, Honiara

Koenig CC, Coleman FC, Collins LA, Sadovy Y, Colin P (1996). Reproduction in gag, Mycteroperca microlepis (Pisces: Serranidae) in the eastern Gulf of Mexico and the consequences of fishing spawning aggregations. In: Arreguin-Sánchez F, Munro JL, Balgoes MC, Pauly D (eds) Biology, fisheries and culture of tropical groupers and snappers. ICLARM Conf Proc 48:307-323

Leis JM (1986) Larval development in four species of the Indo-Pacific coral trout Plectropomus leopardus (Pisces: Serranidae: Epinephelinae) with an analysis of the relationships of the genus. Bull Mar Sci 38:525-552

Mapstone BD, McKinlay JP, Davies CR (1996) A description of the commercial reef line fishery logbook data held by the Queensland Fisheries Management Authority. Report to the QFMA from the CRC Reef Research Centre and the Department of Tropical Environment Studies and Geography, James Cook University, Townsville

Richards A (1993) Live reef fish exports to South-East Asia from the South Pacific. SPC Fish Newsl 67:34-36

Rimmer MA, Garrett RN, Samoilys MA (1994) In vitro fertilization of eggs of coral trout, Plectropomus leopardus (Serranidael, collected from an aggregation site on the Great Barrier Reef, Australia. Bull Mar Sci 54(1):356-358

Robertson DR (1972) Social control of sex-reversal in a coralreef fish. Science 177:1007-1009

Robertson DR (1991) The role of adult biology in the timing of

Editorial responsibility: David Klumpp (Contributing Editor), Townsville, Australia spawning of troplcal reef fishes. In: Sale PF (ed) The ecology of fishes on coral reefs. Academic Press Inc, San Diego, p 356--386

Robertson DR, Petersen CW, Brawn JD (1990) Lunar reproductive cycles of benthic-brooding reef fishes: reflections of larval biology or adult biology? Ecol Monogr 60: $311-329$

Sadovy Y (1994) Grouper stocks of the western central Atlantic: the need for management and management needs. Proc Gulf Carib Fish Inst 43:43-64

Sadovy $Y$ (in press) The case of the disappearing grouper: Epinephelus striatus, the Nassau grouper, in the Caribbean and western Atlantic. Proc Gulf Carib Fish Inst 45

Sadovy YJ (1996) Reproduction of reef fishery species. In: Polunin NVC, Roberts CM (eds) Management of reef fisheries. Chapman \& Hall, London, p 15-59

Sadovy Y, Domeier ML (1994) Aggregation and spawning in the tiger grouper, Mycteroperca tigris (Pisces: Serranidae). Copeia 1994(2):511-516

Sadovy Y, Rosario A, Roman A (1994) Reproduction in an aggregating grouper, the red hind, Epinephelus guttatus. Environ Biol Fishes 41:269-286

Samoilys MA (1987) Aspects of the behaviour, movements and population density of the coral trout, Plectropomus leopardus (Lacepede) (Pisces: Serranidae) at Heron Island, southern Great Barrier Reef. MSc thesis, Queensland University, Brisbane

Samoilys MA, Squire LC (1994) Preliminary observations on the spawning behavior of coral trout. Plectropomus leopardus (Pisces:Serranidae), on the Great Barrier Reef. Bull Mar Sci 54(1):332-342

Shapiro DY (1979) Social behavior, group structure, and the control of sex reversal in hermaphroditic fish. Adv Study Behav 10:43-102

Shapiro DY (1987) Reproduction in groupers. In: Polovina JJ, Ralston S (eds) Tropical snappers and groupers: biology and fisheries management. Westview Press, Boulder, p 295-327

Shapiro DY, Hensley DA, Appeldoorn RS (1988) Pelagic spawning and egg transport in coral reef fishes: a skeptical overview. Environ Biol Fishes 22:3-14

Shapiro DY, Sadovy Y, McGehee MA (1993) Size, composition, and spatial structure of the annual spawning aggregation of the red hind Epinephelus guttatus (Pisces: Serranidae). Copeia 2:399-406

Siegel J (ed) (1992) Statistix. Version 4.0 user's manual. Analytical Software, St Paul

St John J (1996) Feeding ecology of the coral trout, Plectropomus leopardus (Serranidae) on the Great Barrier Reef, Australia. PhD dissertation. James Cook University, Townsville

Thresher RE (1984) Reproduction in reef fishes. TFH Publications lnc, Neptune City, NJ

Tucker JW, Bush PG. Slaybaugh ST (1993) Reproductive patterns of Cayman Island Nassau grouper (Epinephelus striatus) populations. Bull Mar Sci 52(3):961-969

Vincent ACJ, Sadovy Y (in press) Reproductive ecology in the conservation and management of fishes. In: Caro TM (ed) Behavioural ecology and conservation biology. Oxford University Press, Oxford

Zar JH (1984) Biostatistical analysis, 2nd edn. Prentice-Hall Inc, Englewood Cliffs, NJ

Submitted: February 5, 1997, Accepted: October 6, 1997

Proofs recelved from author(s): November 28, 1997 